\title{
Toward New Ideas on the Control of Pesticide Application: A Low-cost Tunnel Sprayer for Vineyards
}

\author{
Antonio Odair Santos, Claudio Alves Moreira, \\ Antonio Carlos Loureiro Lino, Hamilton Humberto Ramos
}

\begin{abstract}
A prototype of recycling sprayer was tested in a vineyard with the aim to analyze the distribution of spray in the canopy leaves and the general spraying efficiency. The sprayer was developed at the Instituto Agronômico (IAC) at the Centro de Engenharia Agrícola, located in Jundiaí (São Paulo State, Brasil). The experiment was carried out from 2017 to 2109. The nozzles were fitted inside air spouts placed along vertical air ducts, located so that two converging air jets reached the canopy in two different opposite positions. Two vertical panels $(1,20 \mathrm{~m} x$ $1,90 \mathrm{~m}$ ) were installed on the same folding arms on which the air ducts are placed. The machine was enabled to perform electrostatic spraying. Excess liquid collected on the bottom of the panels were sucked back into the tank by a micro hydraulic pump. The prototype was submitted to field tests to verify the leaf spray coverage and the capability of the machine to save active ingredient during the spray. Leaf image analysis was used to study leaf spray coverage in field tests. The recycling device confirmed its efficiency with a saving of about $50 \%$ of active ingredients at the end of the treatments, and the use of electrostatic spray was beneficial for the leaf coverage uniformity, for spraying under high liquid pressure.

Index Terms - Viticulture, spraying, disease control.
\end{abstract}

\section{INTRODUCTION}

In the tropical viticulture, disease control is an important issue for the grape growers, as it can affect the vine all along the seasons. Moreover, the increasingly public concern about environmental pollution, which can be observed in the recent years, has brought under the spotlight the problem of pesticide target loss during spray application in the vineyards.

In fact, the results of research carried out in recent years, for conventional spraying, e.g. citrus, point out that even when modern sprayers, with directed jet and tangential airflow are in use, the general values of spray are discouraging. Deposits comprise almost 33\% in the plant, $23 \%$ to the soil and $44 \%$ as evaporation and drift, of the total applied spray dose [4]. This result even though represents a remarkable improvement with respect to the traditional air blast sprayers, which can place in the foliage only $15-35 \%$ of the total distributed liquid, unfortunately does not show

Antonio Odair Santos, Centro de Engenharia/CEA, Instituto Agronômico (IAC), Jundiaí (SP), Brasil

Claudio Alves Moreira, Centro de Engenharia/CEA, Instituto Agronômico (IAC), Jundiaí (SP), Brasil.

Antonio Carlos Loureiro Lino, Centro de Engenharia/CEA, Instituto Agronômico (IAC), Jundiaí (SP), Brasil.

Hamilton Humberto Ramos, Centro de Engenharia/CEA, Instituto Agronômico (IAC), Jundiaí (SP), Brasil. further potential of advancement.

Consequently, taking into consideration the low efficiency of common spraying techniques, loss-reducing methods have become necessary in order to maximize the pesticide spray efficiency in the canopy. Furthermore, the leaf coverage uniformity is also important for disease control so that, nowadays, the electrostatic spray is an important auxiliary technology for improving the leaf spray coverage.

During recent years several devices, such as air conveying devices and anti-drift nozzles were proposed and tested [9], [11], together with electronic sensors to adjust the spray to the crop [10], [14, [13]. In this view, recycling sprayers appear to be very promising [21], [17], because they can recover part of the active ingredient thus reducing the real applied dose. Furthermore, electrostatic spray can be added to recycling sprayers as an artifact for volume reduction in the spraying of vineyards.

In this view, this work aimed to develop a recycling tunnel sprayer to be used in vineyards and, in addition, to verify their general performance in the field, using leaf image analysis to determine leaf coverage uniformity.

\section{METHOD}

The experiment was carried out in the Centro de Engenharia e Automação/IAC, located in Jundiaí (Sao Paulo State, Brasil). The field tests were performed in a vineyard of the cultivar 'Isabel', established in the espalier system, spacing in $3 \mathrm{~m} \times 2 \mathrm{~m}$. The research was performed from 2017 to 2019. The experiment was a completely randomized design, and when necessary the means were compared by Tukey's test set at 5\% probability with the help of the statistical analysis program SISVAR [8].

The prototype was equipped with a centrifugal fan and flexible air ducts; spray atomization was obtained by the spray nozzles (Teejet $囚$ : empty conical jet), displaced along two vertical air ducts and located so that two converging air jets reach the canopy in two different opposite positions.

A recycling device was assembled by adding two vertical panels $(1.2 \mathrm{~m} \times 1.9 \mathrm{~m})$, pending from sustaining arms, in which the air ducts are placed, and a horizontal panel was placed to cover the panels.

Each of the spraying units, or single panel (Fig.1) consisted of an asymmetrical shield, each including: -forced air from centrifugal flow fan (maximum air flow rate: $1.2 \mathrm{~m}^{3} / \mathrm{s}$ ), a vertical air duct (Height: $1.8 \mathrm{~m}$; diameter: $0.2 \mathrm{~m}$ ), fitted with 
six air jets (total outlet section: $58 \mathrm{~cm}^{2}$ ), spaced at $0.2 \mathrm{~m}$ intervals.

Excess liquid was collected on the bottom of the panels by a 1-bar pressure pump (flow rate $5 \mathrm{~L} / \mathrm{min}$ ), which after filtration, returns the recovered mixture to the spray tank.

The distance between the panels can be adjusted from 0.2 up to $1.0 \mathrm{~m}$ by means of a hydraulic pump, plus pinion and rack mechanism. The panels were enabled to move altogether by means of a hydraulic cylinder.

The sprayer was completed with a 400 L spray tank, a pressure regulator, and an oil pressure system (electric-overhydraulic). A hydraulic power system, driven by the tractor's P.T.O. was used to operate the fans and a piston-type pump on the over-the-row structure.

The system included a lamellae screen located in the inner side of the recycling panels intended to separate the droplets from the airstream coming from the canopy.

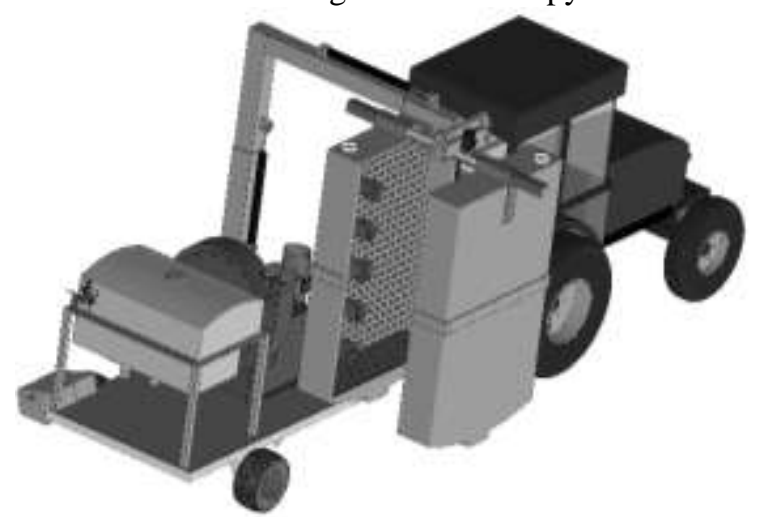

Figure 1. CAD Design of the assembly of the recycling device.

Recovery rate in laboratory

In the laboratory, the performance of the sprayer was evaluated based on spray recovery trials, with water only, under static conditions, and in the absence of vegetation. The sprayer was fitted with 10 open cone nozzles, and the averaged medium flow rate was $7.92 \mathrm{~L} / \mathrm{min}$ (at $345 \mathrm{kPa}$ ) in all experiments. The spray recovery rate was measured by collecting the water flow from the tube of the recycling system, previously disconnected from the tank. This involved adjusting the operational parameters of the sprayer: starting the sprayer and waiting until the water flow from the recycling pipe became steady; placing the end of the tube in a container (Volume capacity: $50 \mathrm{~L}$ ), to collect the water flow; after four minutes, removing the tube's end and measuring the volume of water collector using graduated cylinders. In each test, the machine was allowed to spray for at least three minutes before taking the first measurement.

Two different tests were performed, in which the following settings were compared: - tunnel opening: $0.50 \mathrm{~m}$, and $1.00 \mathrm{~m}$; - with fan speed at 1500 RPM, corresponding to air flow rates of $2.10 \mathrm{~m}^{3} / \mathrm{s}$, respectively.
Recovery rate and spray deposit distribution in the vineyard

Another experiment was conducted in a vineyard aiming to analyze the distribution of spray into the canopy, onto the soil and the off-target dispersion of the spray. In addition, it was also verified the capability of the machine to save active ingredient during the spray application

Two vine rows were randomly selected in the vineyard, and six absorbing paper stripes were displaced on the soil. The absorbing stripes were spaced by $15 \mathrm{~m}$, down in the planting row, to verify the eventual drop of liquid onto the soil.

After the applications, 60 leaves and 60 bunches, per row, were randomly collected and packaged in identified plastic packages. Paper samples were also recollected, identified and placed in plastic bags.

Subsequently, spray deposits were assessed with the procedure described by [15]. Each sample was washed using $100 \mathrm{~mL}$ deionized water (leaves) or $200 \mathrm{~mL}$ (paper samples and bunches). Optical absorbance at $425 \mathrm{~nm}$ wavelength was assessed with a spectrophotometer (UV-VIS, Spectrum SP-2000), and spray deposits (d, in $\mu \mathrm{L})$ were calculated as:

$$
d=10^{3} \frac{w A}{A_{m}}
$$

where $\mathrm{w}$, in $\mathrm{mL}$, is the volume of water used to remove the tracer; A the absorbance of the washing solution; $A_{m}$ the absorbance of the applied spray mixture. Deposits were then expressed in $\mu \mathrm{L} / \mathrm{cm}^{2}$ of leaf area (i.e., the total area of both leaf sides), $\mu \mathrm{L} / \mathrm{cm}^{2}$ ground area (paper samples), or $\mu \mathrm{L} / \mathrm{g}$ fresh weight (bunches). Results were converted to percentage of applied volume.

Along the experiment, for any row used in the trial, six vines were randomly chosen for the assessment of the averaged leaf area index (LAI). A computational algorithm (Vitiscanopy) was used to calculate the LAI [6]. It uses the in locus` image analysis to calculate the canopy architectural parameters, which are based on gap analysis from upward-looking images of canopies and the transmission of light through the canopy to estimate LAI based on Beer's Law [6].

\section{Leaf coverage in varied spray configuration}

A set of experiments were designed, for different dates, and it was verified the capability of the machine to cover the leaves with the active ingredient under certain conditions: a) electrostatic and conventional spray; b) comparison with traditional spray application technique (Air blast Sprayer).

Vine rows were randomly selected, and a completely randomized design was set.

The application of liquid was performed under a pressure of $345 \mathrm{kPa}$, with tractor`s PTO speed of $540 \mathrm{RPM}$. The speed of application was $3.5 \mathrm{~km} / \mathrm{h}$. The volume of liquid applied was $100 \mathrm{~L} / \mathrm{ha}$. Yellow-Saturn was used as marker of the applied liquid, in the proportion of $1 \mathrm{~g} / \mathrm{L}$ of water.

In the vineyard, four rows were randomly selected for analysis of leaf coverage, and the leaves were sampled in the inner and outer portions of the upper, middle and lower thirds of the canopy, totaling 60 samples.

The leaves were collected with the help of scissors and stored in a paper bag and taken to the lab. During the 
application, the temperature varied between 24.5 and $26^{\circ} \mathrm{C}$, the relative humidity between 55 and $60 \%$ and the wind speed between 1.5 and $3,5 \mathrm{~m} . \mathrm{s}^{-1}$.

After each application, six vines were randomly chosen in the analyzed rows, for the assessment of the leaf area index (LAI) [6].

Each sample from the rows was taken to the laboratory and fixed on a white plate to facilitate separation of the leaves and the background. The leaves were photographed in a dark environment, under ultraviolet light, to evidence the drops containing the fluorescent marker. A Canon digital camera (model EOS Rebel T5) was used with especial lenses (Canon EF $50 \mathrm{~mm}$ ), positioned at a distance of $40 \mathrm{~cm}$.

The images obtained were processed and analyzed in the ImageJ software (National Institute of Mental Health, Ca, USA), for which a computational routine was developed with the purpose of automating these operations and finally segregating the total droplet coverage in the leaf blades.

\section{RESULTS}

Results from the relation between liquid pressure and flow rate are shown in the Fig. 2.

Analyzing the curves together it is noted that, generally, within the adopted pressure interval, a flow control can be made, which ranges from an average of $1200 \mathrm{ml} . \mathrm{min}^{-1}$ to 1900 $\mathrm{ml} . \mathrm{min}^{-1}$. This represents an adequate amplitude for application rates of a wide range of pesticides, from ultra-low volume to high volume.

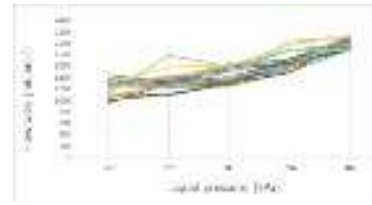

Figure 2. Relation between water flow rate and pump pressure for the recycling sprayer.

The laboratory test for varied distance between the tunnel's walls shows a maximum recovery rate of $97.3 \%$ in a static test (Table 1). The reduction in the recovery rate at increasing distances between the tunnel's walls was largely expected. Therefore, a minimum of $60.5 \%$ recovery rate was recorded at the $1,0 \mathrm{~m}$ distance, in the absence of air flux. Turbulence is responsible for the generation of greater losses at larger distances. However, with no fan, the water flux without the help of air stream causes the flux of droplets to be diverted to outside of the shields.

During the tests was noticed that the spray recovery rate was little affected by the air flow rate adjustments. This is promising in face of the work outside in the field, since it suggested that it would be possible to adjust for a correct air flow rate to get better liquid penetration. This can help to reach leaves in the internal part of vine canopy, during spray application in the vineyard, without affecting the potential recovering rate of the sprayer.

Results from a Table 1 suggests that that the increase in the distance between the shields makes the recovery worse, so shields should be used as close as possible, in accordance to the vine canopy size.
Table 1. Averaged values for recovery rate, for three runs of static test for pressurized liquid $(345 \mathrm{kPa})$ and not pressurized liquid.

\begin{tabular}{|c|c|c|c|}
\hline \multirow{2}{*}{\begin{tabular}{c} 
Tunnel \\
\cline { 2 - 4 } opening
\end{tabular}} & $\begin{array}{c}\text { Liquid } \\
\text { pressure } \\
\text { (no fan) }\end{array}$ & $\begin{array}{c}\text { Ran } \\
\text { pressurization } \\
(\mathrm{m})\end{array}$ & $\begin{array}{c}\text { Averaged air } \\
\text { flow within } \\
\text { the inlets } \\
(\mathrm{m} / \mathrm{s})\end{array}$ \\
\hline 0.50 & $75.1 \pm 1.0 \quad \mathrm{a}$ & $95.0 \pm 0.1 \quad \mathrm{c}$ & 9.2 \\
\hline 0.50 & $76.3 \pm 0.61 \mathrm{a}$ & $97.3 \pm 0.5 \mathrm{c}$ & 9.2 \\
\hline 1.0 & $60.5 \pm 1.4 \quad \mathrm{~b}$ & $81.4 \pm 1.0 \mathrm{~d}$ & 9.2 \\
\hline 1.0 & $62.0 \pm 0.9 \quad \mathrm{~b}$ & $83.0 \pm 1.0 \mathrm{~d}$ & 9.2 \\
\hline
\end{tabular}

In the test carried out to verify the deposit distribution in the vineyard, the liquid recovery rate ranged from a maximum $53.3 \%$ to a minimum $39.4 \%$ (Table 2 ).

There is a decrease in the values, as now one has the presence of the canopy, as compared to the static test depicted in the Table 1, without the presence of the vegetation. According to Table 2, the major part of applied volume was retained in the canopy, with similar values between rows. A small fraction was diverted to the soil, being the rest considered as drift plus evaporation.

There was an increase in the drift values in the row three, which could be due to increased variation in the wind speed during application or eventual increased deposition onto the vineyard structure (posts and wires), deposition on parts of the vines other than leaves (trunks, stems, petioles), deposition on the sprayer itself. Most of this deposition in the inside part of the machine and in the lamellae installed in the inner part of the shields.

Table 2. Averaged Spray deposition and losses (\% of volume applied), for three rows in a vineyard, during the 2018 growing season; liquid pressure at $345 \mathrm{kPa}$; fan pressurization at $1500 \mathrm{RPM}$

\begin{tabular}{|c|c|c|c|c|c|}
\hline \multirow[b]{2}{*}{$\underline{\text { Row }}$} & \multirow[b]{2}{*}{$\begin{array}{c}\text { Volume } \\
\text { Applied } \\
\text { (L/ha) }\end{array}$} & \multirow[b]{2}{*}{$\begin{array}{l}\text { Recovery } \\
\text { rate }(\%)\end{array}$} & \multicolumn{3}{|c|}{ Total distributed (\%) } \\
\hline & & & $\begin{array}{c}\text { Canopy } \\
\text { and } \\
\text { bunches }\end{array}$ & Soil & $\begin{array}{l}\text { Drift and } \\
\text { evaporation }\end{array}$ \\
\hline$\underline{\mathrm{R}} 1$ & 200 & $\underline{53.3}$ & $\underline{42.8}$ & 2.3 & 2.7 \\
\hline$\underline{\mathrm{R} 2}$ & 200 & 49.2 & 46.5 & 3.3 & 1.0 \\
\hline$\underline{\mathrm{R} 3}$ & $\underline{200}$ & $\underline{39.4}$ & 48.3 & 1.7 & 10.6 \\
\hline
\end{tabular}

Table 3 shows the influence of LAI development on recovery rate. In august third, a date before bud break, the LAI is zero, and the recovery rate is at its highest value. As the LAI unfold during the growing season, the recovery rate shows a decreasing profile, since the canopy increases the interception of applied liquid volume. 
Table 3. Averaged values for recovery rate, in different dates, for two vine rows, under pressurized liquid and at $345 \mathrm{kPa}$ and fan pressurization at $1500 \mathrm{RPM}$.

\begin{tabular}{|l|c|c|c|c|}
\hline $\begin{array}{c}\text { Trial date } \\
(2018)\end{array}$ & LAI & $\begin{array}{c}\text { Tunnel } \\
\text { opening, } \\
(\mathrm{m})\end{array}$ & $\begin{array}{l}\text { Recovery } \\
\text { rate \% }\end{array}$ & $\begin{array}{l}\text { Volume } \\
\text { sprayed } \\
\text { (L/ha) }\end{array}$ \\
\hline Aug-3 & 0 & 0.70 & 69 & 200 \\
\hline Sept-3 & 0.29 & 0.65 & 50 & 200 \\
\hline Sept-11 & 0.53 & 0.60 & 57 & 250 \\
\hline Sept-30 & 0.70 & 0.70 & 50 & 350 \\
\hline Oct-9 & 0.98 & 0.70 & 39 & 400 \\
\hline Nov-3 & 1.60 & 0.70 & 30 & 420 \\
\hline
\end{tabular}

Table 4 and 5 , show some representative samples of the leaf coverage results, obtained using two available spray techniques in the developed prototype, the electrostatic spray (ES) and the traditional spray (TS), with no electrostatic charge.

In the images, the increased black color represents increased leaf coverage.

In most of the investigations involving spraying the total deposits are always considered as a measure of spraying efficiency [3].

However, the distribution of spray in the leaves is an important point to be considered as, for example, the fungi can penetrate the leaf tissues even with a good total deposit which, although does not cover all the leaf blade.

Table 4 and 5 shows good results for spray leaf coverage, even for the internal leaves, were achieved, no matter the technique used.

However, when considering all data and only spray techniques, Table 8, which depicts the output of statistical analysis, shows that there was an improvement in leaf cover by adding electrostatic spray, as compared to the traditional spray results.

Even though, the minimum result for leaf coverage was $27.14 \%$ for traditional spray, and all values for leaf coverage, regardless the spray technique are well above $30 \%$ of leaf coverage (Table 4 and 5).

According to some authors a baseline value of $30 \%$ in leaf coverage was considered enough to protect the orange [18] and sugarcane leaves [19], from disease infection. It wasn't found similar research results for vineyards, however, following the cited authors, all values form Table 4 and 5 are far greater than $30 \%$ which can be considered an adequate level of leaf coverage to protect the vines from diseases.
Table 4. Subsample of spray leaf coverage (\%) for electrostatic spray.

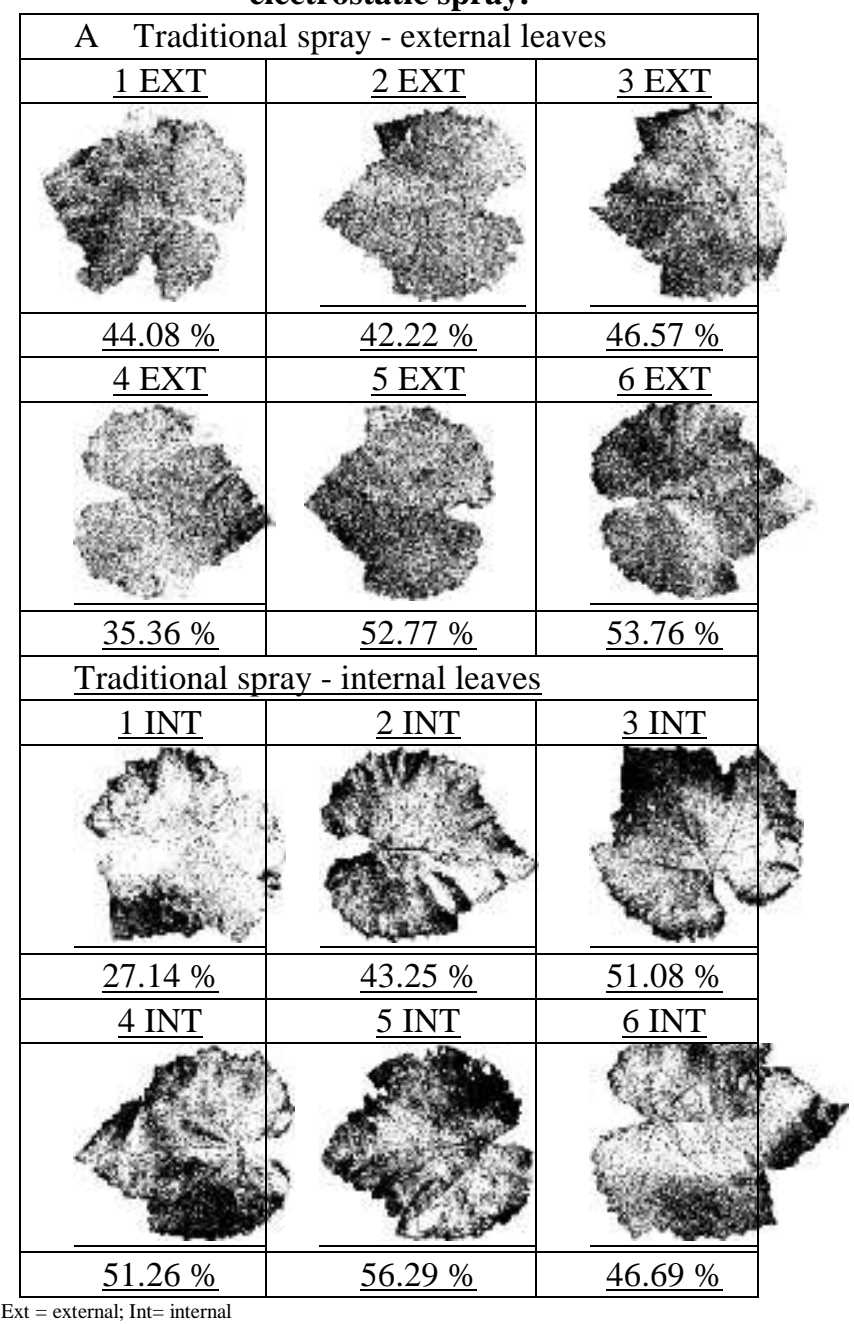

Tables 6 and 7 show the results for spray leaf coverage, using two different spray machines, in a separate experiment. For the air-blast machine, a minimum of $12.48 \%$ in leaf coverage was recorded. However, most of the values are higher than 50\%. Table 6 depicts results of an adequate coverage, even though the losses of spray liquid to the ambient is knowingly always large.

Generally, air-blast machines use a higher liquid pressure to spray small-sized droplets. Traditionally, they use nozzles that also contribute to produce those droplet sizes. The small droplets are transported farther into the canopy than large droplets and provide better coverage inside the canopy. Electrostatic spray, by its turn, depends on air turbulence and electric attraction between the leaves and the charged droplet, to penetrate the canopy depth. 
Table 5. Subsample of spray leaf coverage (\%) for traditional spray.

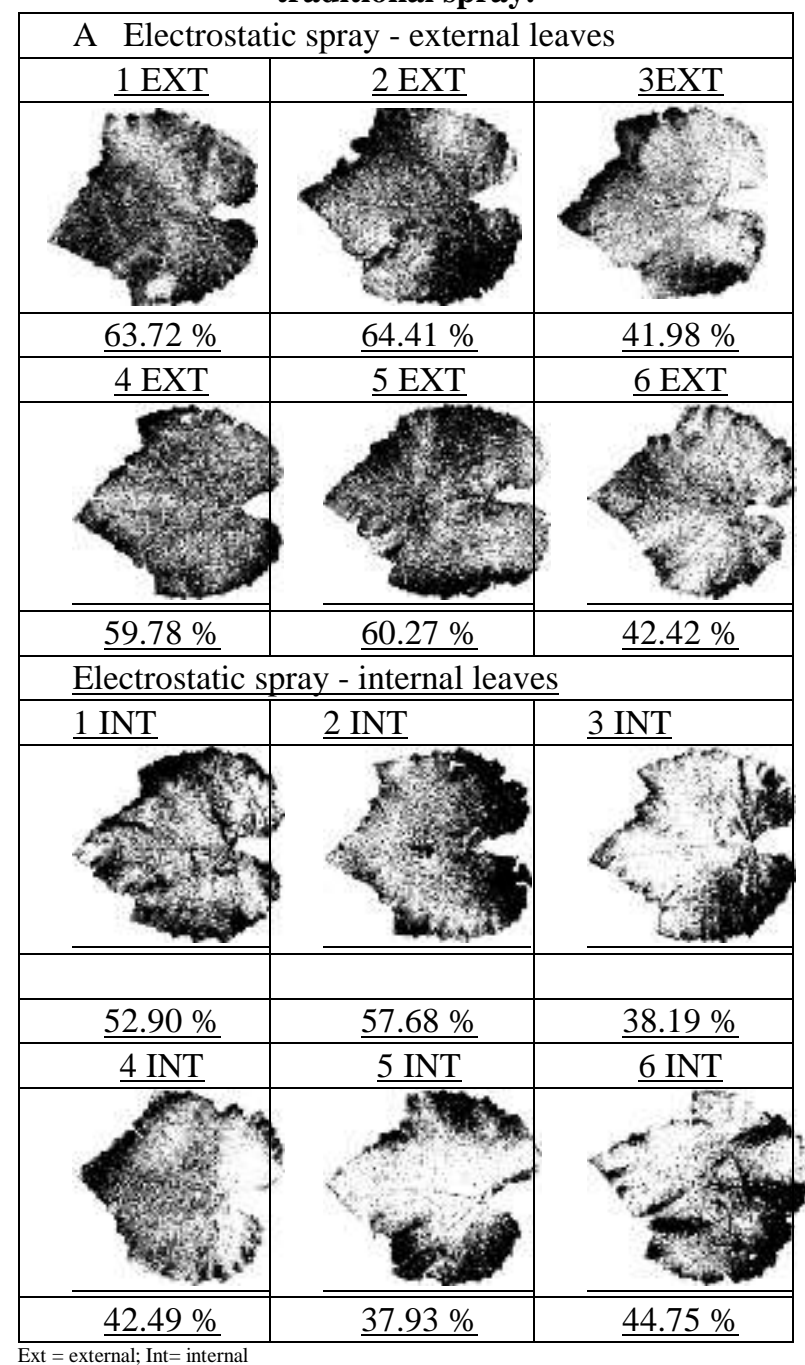

When the prototype was used with the electrostatic option (Table 7), averaged coverage values were higher as compared to the air-blast spray machine. These data are significantly different, according to Table 8 . When adding the values for the traditional spray (TS), in the analysis, highlight the results for electrostatic spray, which were higher and different statistically, as compared to TS and AB.
Table 6. Subsample of spray leaf coverage (\%) for air-blast spray.

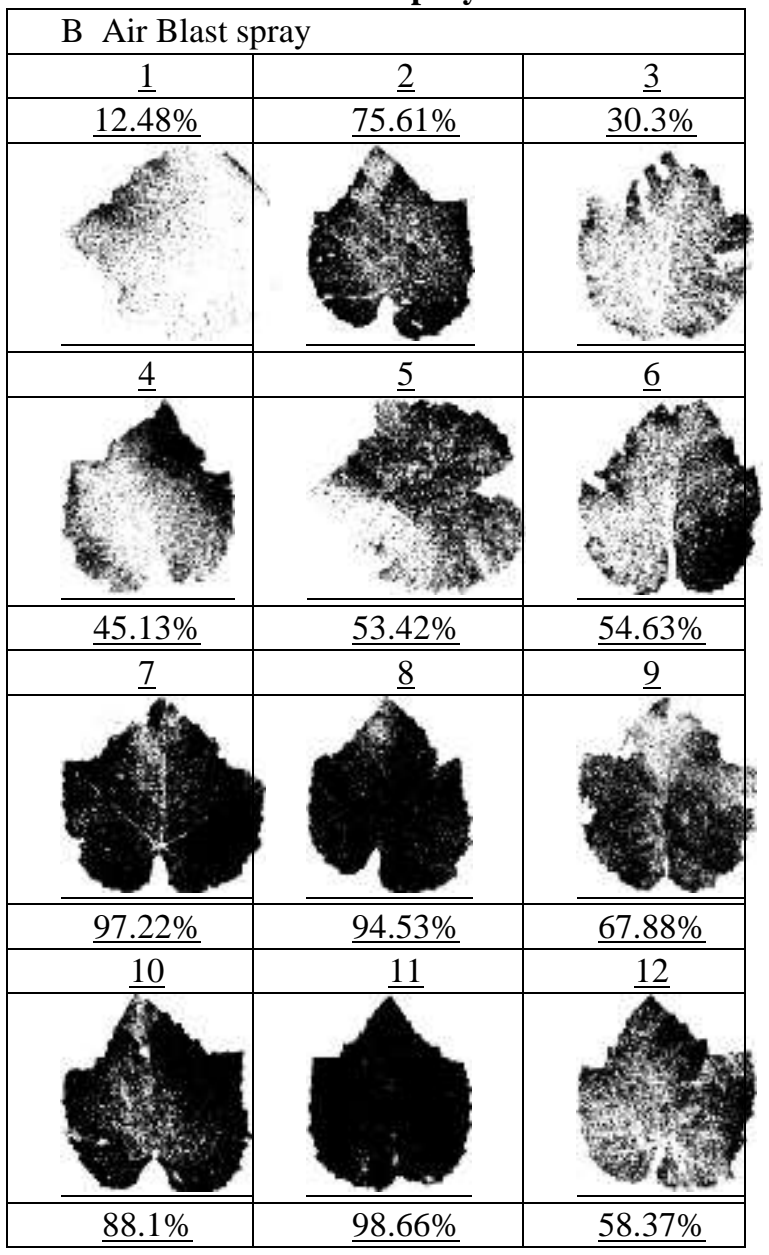

Considering that the spray was performed at high liquid pressure $(345 \mathrm{kPa})$, one can see that, at least at this pressure level, the developed prototype can deliver a adequate spray, when compared to a similar machine, traditionally present in the market (air-blast machine). 
Table 7. Subsample for spray leaf coverage for electrostatic spray.

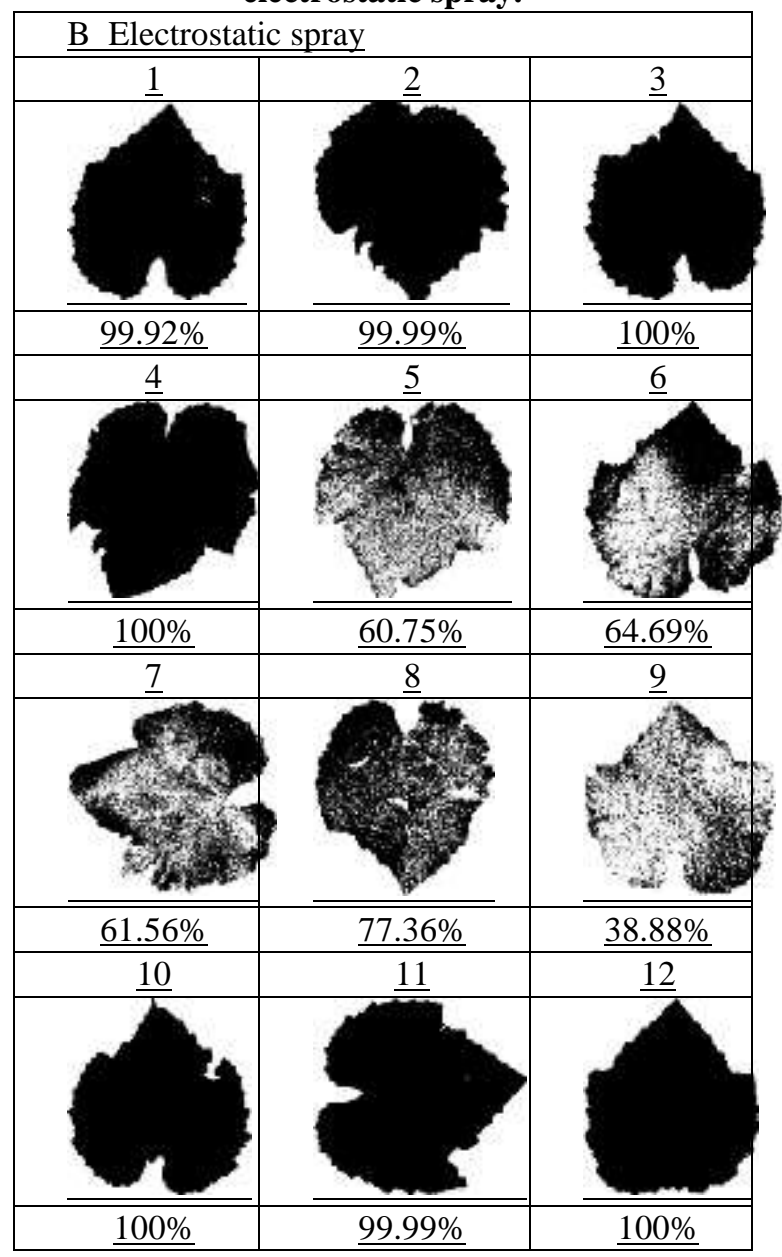

Table 8. Averaged data for spray leaf coverage values according to leaf positioning and spray techniques.

\begin{tabular}{|c|c|c|c|c|c|c|}
\hline \multicolumn{7}{|c|}{ Averaged Spray leaf coverage $(\%)$} \\
\hline \multicolumn{4}{|c|}{ Leaf positioning } & \multirow{2}{*}{\multicolumn{3}{|c|}{ Spray technique }} \\
\hline \multicolumn{2}{|c|}{$\begin{array}{l}\text { Electrostatic } \\
\text { (ES) }\end{array}$} & \multicolumn{2}{|c|}{$\begin{array}{l}\text { Traditional } \\
\text { (TS) }\end{array}$} & & & \\
\hline$\underline{\text { Int }}$ & $\underline{\underline{E x t}}$ & $\underline{\text { Int }}$ & $\underline{E x t}$ & $\underline{\mathrm{ES}}$ & $\underline{\mathrm{TS}}$ & $\underline{\mathrm{AB}}$ \\
\hline 45.66 & $\underline{55.43}$ & 45.95 & 46.63 & $\underline{83.60}$ & 45.87 & 64.69 \\
\hline$\underline{\mathrm{a}}$ & $\underline{\mathrm{a}}$ & $\underline{\mathrm{a}}$ & $\underline{\mathrm{a}}$ & $\underline{\mathrm{a}}$ & $\underline{\mathrm{b}}$ & $\underline{\mathrm{a}}$ \\
\hline
\end{tabular}

Data followed by the same letter do not differ by Tukey test $(\mathrm{P}<0,05)$. Int=internal leaves; Ext= external leaves; $\mathrm{ES}=$ =electrostatic spray; $\mathrm{TS}$ - traditional spray; $\mathrm{AB}=$ air-blast spray

\section{DISCUSSION}

Laboratory and field tests have shown to be advantageous the application of a recycling sprayer, based on air assisted system and thin-walled, self-leveling aluminum containment shields, which provided a high recovery rate of the applied ingredient to the vine. In fact, the potential recovery under static conditions was $60.5 \%$ to $97.3 \%$ at $0.50 \mathrm{~m}$ and $1.00 \mathrm{~m}$ shield openings, respectively, and clearly decreased by 1.00 $\mathrm{m}$, suggesting that better performance is expected when using the recycler prototype on proper-managed vertical shoot positioning canopies.

Under dynamic conditions, however, the maximum spray recovery rate decreased due to the presence of the canopy, and the effect of additional wind flow, entering the tunnel from the front opening, even at low operating speeds $(3,5$ $\mathrm{km} / \mathrm{h}-4 \mathrm{~km} / \mathrm{h}$ ). Adjusting a stripped plastic curtain on the front and back could partially offset this effect, resulting in an even higher recovery rate.

Henceforth, this also suggests that the prototype can be improved by increasing the forced air flow rate, or by using additional air jets to protect the front and rear openings of the panels by forming protective air curtains. This detail may increase the degree of confinement.

The actual recovery rate of applied liquid, in the vineyard, was maximum before bud break (69\%), but still moderate rates $(30 \%$ to $57 \%)$ throughout the grapevine growing season and was, as expected, affected by the development of the LAI.

These values were generally better than those reported in the literature for sprayers, either without forced air assistance [5], [2], or equipped with axial fans [12], [17].

The drift rates observed in the field were, as expected very low as compared to the ones observed in traditional not-tunneled machines. The same low values were noticed for the spray loss onto the soil. Other authors working with various crops also showed similar drift or soil spray loss values for fruit in general [7] and, particularly, for grapevine [1].

As shown, a tunnel sprayer may not only reduce drift and improve leaf deposit; it also makes possible the collecting and reusing the overspray.

Total leaf and bunches deposition found in this experiment ranged from $42.8 \%$ to $48.3 \%$, being close to values found elsewhere with a similar axial-fan sprayer previously tested under comparable conditions [1], [16]. The differences can be attributed to the variations in LAI, since, as demonstrated, leaf deposition tends to increase when leaf area increases.

The major advancement in tunnel spray application technology in the near future could be in the area of matching the sprayer characteristics to the target canopy. This could be accomplished by using a system of sensors that detect the height, shape, and density of the tree and adjust the sprayer.

Several methods of measuring the plant size and shape have been used: ultrasonic sensors [10], infrared, machine vision [20]. The last authors concluded that measured plant structure could be used to adjust applied spray ingredients, and this would reduce the amount of pesticide required.

An imagery system would measure the plant structure and calculate the air velocity, spray application rate, and spray droplet spectrum for each directed jet. Each directed jet could be individually turned toward the parts of the tree with denser foliage or greater disease pressure to give optimum spray coverage. The jet velocity could also consider the ambient wind velocity to ensure an optimum canopy penetration. The direction of the directed jets could also consider the location of target pests, i.e., on top or bottom of leaves, in center of plant canopy or on edges.

All these operations will occur as the sprayer moves down in the row. This type of spray control should provide still more uniform leaf coverage with a minimum of spray drift, possibly close to zero. 


\section{REFERENCES}

[1] Anifantis, A. S., Pascuzzi, S, Santoro, F. In: IX International Scientific Symposium "Farm Machinery and Processes Management in Sustainable Agriculture", Lublin, Poland. (2017). Applied Biology 57: Pesticide Application, 285-292.

[2] Baldoin, C., de Zanche, C., Sorgato F., Zanardi, W. Performances of a new shielded sprayer on vineyard. Annual Review of Agricultural Engineering. 1 (2005) 257-265.

[3] Chaim, A. Pulverização eletrostática com bicos hidráulicos. Revista ecotoxicologia e meio ambiente. 17 (2007) 67-74.

[4] Chaim, A., Pessoa, M. C. P. Y.,Ferracini, V. L. Eficiência de pulverização em videira, comparando bicos e pulverizadores. Pesticidas: revista de ecotoxicologia e meio ambiente. Curitiba. 14 (2004) $39-46$.

[5] Cross, J.V., Walklate, P.J., Murray, R.A., Richardson, G.M. Spray deposits and losses in different sized apple trees from an axial fan orchard sprayer: 3 . Effects of air volumetric flow rate. Crop Protection. 22 (2003)381-394.

[6] De Bei R., Fuentes S., Gilliham M., Tyerman, S., Edwards E., Bianchini, N., Collins, C. VitisCanopy: A free computer app to estimate canopy vigor and porosity for grapevine. Sensors. 16 (2016) 585-595.

[7] Doruchowski, G., Holownicki, R. Crop Protection. 19 (2000) 617-622.

[8] Ferreira, D. F. Sisvar: a computer statistical analysis system. Ciência e Agrotecnologia. 35 (2011) 1039-1042.

[9] García-Ramos, F.J., Serreta, A., Boné, A., Vidal, M. Applicability of a 3D Laser Scanner for Characterizing the Spray Distribution Pattern of an Air-Assisted Sprayer. Journal of Sensors. 1 (2018) 1-7.

[10] Gil, E., Rosell, J., Planas, S., Val, L. Variable rate application of plant protection products in vineyard using ultrasonic sensors. Crop Protection. 26 (2007) 1287-1297.

[11] Gregorio, E., Torrent, X., Planas, S., Rosel-Polo, J.R. Science of the Total Environment. 687 (2019) 967-977.

[12] Knewitz, H, Weisser P, Koch, H. Drift-reducing spray application in orchards and biological efficacy of pesticides. International advances in pesticide application. 66 (2002) 231-236.

[13] Maghsoudi, H., Minaei, S., Ghobadian, B., Masoudi, H. Computers and Electronics in Agriculture. 112 (2015) 149-160.

[14] Pérez-Ruiz, M., Agüera, J., Gil, J.A. Optimization of agrochemical application in olive groves based on positioning sensor. Precision Agriculture. 12 (2011) 564-575.

[15] Pergher, G., Petris, R. Canopy structure and deposition efficiency of vineyard sprayers. Journal of Agriculture Engineering. 2 (2007) 53-60.

[16] Pergher, G., Gubiani, R. The effect of spray application rate on foliar deposition in a hedgerow vineyard. Journal of Agricultural Engineering Research. 61 (1995) 205-216.

[17] Pergher, G., Gubiani, R., Sirio, R.S., Cividino, S.R.S., Dell'Antonia, D., Lagazio, C. Crop Protection. 45 (2013) 6-14.

[18] Ramos, H. H., Yanai, K., Corrêa, I. M., Bassanezi, R. B., Garcia, L. C. Características da pulverização em citros em função do volume de calda aplicado com turbopulverizador. Engenharia Agrícola.27 (2007) 56-65.

[19] Schneider, J. L., Oliveira, G. M., Balan, R. E., Canteri, M. G., Saab, O. J. G. A. Cobertura de gotas de pulverização obtida com diferentes pontas e taxas de aplicação na parte aérea da cana-de-açúcar. Ciência Rural, 43 (2013) 797-802.

[20] Walklate, P. J., G. M. Richardson, J. V. Cross, M. R. A. Relationship between orchard tree crop structure and performance characteristics of an axial fan sprayer. Applied Biology. 57 (2018) 285-292.

[21] Wenneker M., Van de Zande, J. Drift reduction in orchard spraying using a cross flow sprayer equipped with reflection Shields. The CIGR E-journal. 10 (2008).

Antonio Odair Santos. Education: Universidade do Estado de Santa Catarina (Lages, SC) (B.Sc); Universidade Federal do Rio Grande do Sul (Porto Alegre, RS) (M.Sc. and D.Sc.); California State University-Fresno (PostDoc.).

Cláudio Alves Moreira. Education: Universidade de São Paulo (Piracicaba, SP) (B.Sc.); University of Illinois, Urbana-Champain (M.Sc.).

Antonio Carlos Loureiro Lino. Education: Universidade de Lavras (Lavras, MG) (B.Sc.); Universidade de Campinas (M.Sc. and D.Sc.).

Hamilton Humberto Ramos. Universidade Estadual Paulista Júlio de Mesquita Filho (Jaboticabal, SP) (B.Sc., M.Sc. And D.Sc.) 